\title{
Leisure and the Life-Cycle Squeeze among Young Adults in North Africa Countries
}

\author{
Ken Roberts $^{1} \cdot$ Siyka Kovacheva $^{2} \cdot$ Stanimir Kabaivanov $^{2}$
}

Received: 3 October 2017 / Accepted: 13 October 2017 / Published online: 28 November 2017

(C) The Author(s) 2017. This article is an open access publication

\begin{abstract}
This paper presents quantitative evidence from surveys of nationally representative samples of approximately 2000 15-29 year olds in each of four North Africa countries (Algeria, Egypt, Morocco and Tunisia). The aim is to test whether the life cycle squeeze on leisure time, money and activities, recorded in successive Western investigations, operates in similar ways in contrasting economic (relatively poor) and Arab-Islamic cultural contexts. The results show that there is a life cycle squeeze in North Africa, and as in the West, it affects women's leisure more powerfully than men's. The findings add to previous knowledge in showing that in North Africa contexts it is marriage rather than housing transitions that is responsible for the greater part of the life cycle squeeze. Finally, it is also proposed the similar socio-economic structures in modern and modernising societies will impose similar patterns (like the life cycle squeeze) on leisure in all such countries, but that the details of exactly how leisure is used will always be infused by traditional occidental, Arab-Islamic or Asian cultures.
\end{abstract}

Keywords Family $\cdot$ Housing $\cdot$ Leisure $\cdot$ North Africa $\cdot$ Youth

\section{Introduction}

This paper uses evidence from surveys of nationally representative samples of 1529 year olds in four North Africa countries to examine whether the 'life cycle squeeze' on leisure during family and housing life stage transitions, which has been confirmed in

This paper has been prepared within the research project FP7-SSH-2013-2 SAHWA: empowering the young generation; towards a new social contract in South and East Mediterranean countries.

Ken Roberts

k.roberts@liverpool.ac.uk

1 University of Liverpool, Liverpool, UK

2 University of Plovdiv, Plovdiv, Bulgaria 
successive Western investigations, is present in a different and contrasting world region. We therefore intend to contribute to ongoing debates on the various alleged trends and counter-trends towards globalisation, glocalisation, hybridisation and domestication in leisure tastes and practices.

\subsection{The Life Cycle Squeeze}

In 1975 Robert and Rhona Rapoport added the family life cycle (today the term life course is generally preferred) to the sociology of leisure's then expanding research agenda. Using a small number of individual case studies, all from London (UK), they argued that during their lives individuals led three inter-twining careers in paid work, the family and leisure, and that during specific life stages, including young adulthood, this entwining created characteristic interests and pre-occupations which were expressed in characteristic uses of leisure. Shortly afterwards Estes and Wilenski (1978) noted in the USA that leisure time and activities were squeezed when young couples embarked on new family and household formation and faced competing demands on their time and money.

All subsequent research has confirmed the operation of this life cycle squeeze. In the UK Gershuny's time use research has shown that leisure activities typically change slowly with age except during major transitions, such as in young adulthood, which require major leisure adjustments (Gershuny 2003). Other research has nuanced this finding. It has shown that women's leisure changes more than men's leisure (Barrell et al. 1989; Smith 1987; Venn et al. 2008; Wearing 1993). This is despite a historical trend in Western countries towards leisure becoming genderless (Robinson and Godbey 1999). It has also been shown that how couples adjust their leisure is class-related. The higher socio-economic strata are the most likely to have the resources to enable men and women to adjust rather than drop favoured leisure activities (Fishwick and Hayes 1989; Sullivan 2010). However, up to now this stream of research has been confined to Western countries.

\subsection{The Internationalisation of the Sociology of Leisure}

Throughout the twentieth century the study of leisure seemed the most naturally international of all sociology's specialisms. Findings in any society - on the relationships between leisure and socio-economic status, age, gender, unemployment or whatever - always travelled virtually intact from country-to-country. However, this was when the sociology of leisure remained an essentially occidental project while bringing together scholars from communist states and the West, countries of the Caribbean and Latin America that were inside the American sphere of political and cultural influence, and former colonies of European powers in which there were substantial settler populations (Canada and Australia for example). The main challenge to occidental scholars' claims to be producing globally valid knowledge about leisure have arisen more recently, and from Asia, where local researchers have resisted the imposition of the Western leisure concept together with its associated verified hypotheses and theories (for example, Iwasaki et al. 2007; Ma and Lui 2017). Meanwhile, the sociology of leisure has been drawn into debates raging in its parent discipline about whether since 1989 all countries have joined the same modernising historical track (Fukuyama 1992) or whether we are entering an era of multiple modernities rather than just two alternatives - socialism and capitalism (Eisenstadt 2000; Martinelli 2007). The 
sociology of leisure can offer plentiful examples of the globalisation of some tastes, sounds and spectacles (see Roberts 2016), but equally of hybridisation, numerous fusions between the global and the local (see Nilan and Feixa 2006; Sivan 2000), and also cases of domestication and increasing demand for local 'authentic' products (Bekuis et al. 2014; Hesmondhalgh 2013).

Up to now there has been little leisure research in North Africa and the Middle East except in Israel from where findings have found a natural home amid the West's leisure scholarship (see, for example, Leitner and Leitner 2014; Nimrod 2007, 2014). Occasional forays into MENA (Middle East and North Africa) by Western leisure scholars have rarely noted more than the immediately evident influence of Islam (the low profile of alcohol for example) (see Ibrahim 1982; Martin and Mason 2003, 2004). Stebbins' (2013) advocacy of serious leisure as a solution to the political problems of the region is surprisingly evidence-free.

The following passages use research evidence from North Africa to test systematically whether findings about the life cycle squeeze, which have proved robust in successive Western contexts, remain valid in the contrasting contexts of mainly Arab and Moslem North Africa countries.

\subsection{Evidence}

Our evidence is from quantitative surveys in 2015-16 using a fully structured questionnaire with nationally representative samples of approximately 2000 15-29 year olds in each of four North Africa countries - Algeria, Egypt, Morocco and Tunisia. All the littoral South Mediterranean states were included in the research except Libya where conditions at the time (civil wars) prohibited the relevant fieldwork. Respondents were residents in the target age group in nationally representative samples of households in each country. Interviews were conducted in the respondents' homes, always by same-sex interviewers.

Funding became available and the research was planned in the aftermath of the events in 2011 that are known as the Arab Spring. At that time it seemed possible that the research would be charting young people's involvement in and responses to the democratisation of their countries and subsequent social and economic transformations, as following 'the events of 1989' in Eastern Europe. In the event only Tunisia had become and remained a multi-party democracy in 2015-16, and rather than developing the region's economies had faltered or contracted. The research therefore became a study of young people's situations, hopes, activities and discontents. The interviews covered all aspects of the respondents' lives - family origins, education and labour market careers, marital status, housing and household composition at the time of the surveys, political and religious orientations and activities, plus uses of free time. The main measurements of the latter were frequency of involvement in 13 leisure activities (specified below) on a six-point scale with a range from never to every day. In our analysis we use 'at least once a week' as the benchmark for comparing participation rates in the different countries and socio-demographic groups. Respondents were also asked about their uses of old and new media, specifically estimates of the typical hours and minutes per day that they spent watching television and online. They were also asked whether they had ever travelled abroad and, if so, how often and the destinations.

Discovering whether family and housing life stage transitions in the region were having similar leisure consequences to those recorded in Western research requires the 
effects of age, marital status and housing to be separated. For this purpose we divide our samples into three age groups - 15-19, 20-24 and 25-29. We can thereby identify age effects holding marital status constant and the differences made by marital status within age bands. We can then compare couples who had, and those who had not, moved into their own independent households. Although only a quite small minority of males and a larger minority of females were married even in the oldest group, the total size of our samples (around 8000) permits the necessary comparisons.

\section{Findings}

\subsection{Context}

It is the different contexts that make it dangerous to assume that any of the relationships between leisure tastes and behaviour, and socio-demographic predictors, that have been found across multiple Western countries will be found, or at least take the same form, in the very different contexts of North Africa countries.

These countries are relatively poor. Table 1 gives the labour market situations of the 25-29 year olds in our samples (by when nearly all had finished full-time education). The data show high rates of labour market inactivity, especially in Egypt. Youth unemployment was an issue everywhere, but was especially prevalent in Tunisia. A more common problem facing the region's youth was job quality. Most of the jobs held by respondents were informal and therefore inherently precariously, and often very low paid. Average monthly earnings of employees ranged from €413 in Egypt to €695 in Algeria. Low incomes will always depress leisure spending, and there has been little public spending on leisure infrastructure in any of the countries except when inward tourists have been the intended beneficiaries.

Gender differences are generally wide, but no longer so in education where participation rates and levels of attainment are now very similar for males and females. The countries have invested heavily in their education systems. The proportions of our 25-

Table 1 Labour market positions, 25-29 year olds, by country

\begin{tabular}{lllll}
\hline & Algeria & Egypt & Morocco & Tunisia \\
\hline & $\%$ & $\%$ & $\%$ & $\%$ \\
Education & 7 & 3 & 11 & 6 \\
Employer & 1 & 2 & 1 & 2 \\
Self-employed & 10 & 3 & 18 & 4 \\
Employee & 29 & 41 & 32 & 25 \\
Apprentice & 2 & - & 4 & 3 \\
Family worker & 2 & 4 & 1 & 2 \\
Unemployed & 15 & 6 & 4 & 29 \\
Inactive & 32 & 41 & 29 & 29 \\
N = & 616 & 606 & 429 & 702 \\
Mean monthly incomes of employees, all ages, in ppp $€$ & 695 & 413 & 519 & 451 \\
\hline
\end{tabular}


29 year olds who were university graduates ranged from $24 \%$ in Egypt to $38 \%$ in Tunisia. Unfortunately, 'knowledge jobs' have not followed this investment in human capital. The proportions of women who are active in the region's labour markets have not been rising. Higher education results in more seeking, but most do not obtain offers of acceptable employment. Meanwhile, the replacement of rural family farms by commercial agri-businesses has reduced opportunities for women in this industry (Farsoun 2006). Thus 55\% of female 25-29 year olds in our surveys were inactive in their countries' labour markets. Most had completed education then stayed at home, 'waiting for the right man', meanwhile assisting mothers and any co-resident sisters with housework and child care (if younger children were present).

Table 2 lists the 'at least once a week' participation rates in the free time activities about which the samples were questioned. In this table respondents are divided according to whether they lived in urban or rural areas, and by gender. The list of free time activities was not plucked from Western research but was drawn up by local research partners. The participation rates will look low to anyone familiar with comparable Western data. Rates of participation were generally higher in urban than in rural areas, and higher among males than among females, especially within the rural settlements. However, participation rates in out-of-home activities tended to be compensated by time spent watching television and time spent online. Until 2000 no private households in the world had broadband and until 2008 no-one had a smartphone. During the initial spread of these latest new technologies the North Africa countries were on the wrong wide of a digital divide, but by 2015-16 this was no longer the case.

Table 2 Uses of free time by respondents' places of residence, all ages, all countries

\begin{tabular}{|c|c|c|c|c|}
\hline & $\begin{array}{l}\text { Rural males } \\
\%\end{array}$ & $\begin{array}{l}\text { Urban males } \\
\%\end{array}$ & $\begin{array}{l}\text { Rural females } \\
\%\end{array}$ & $\begin{array}{l}\text { Urban females } \\
\%\end{array}$ \\
\hline \multicolumn{5}{|l|}{ Take part at least once a week } \\
\hline Go out with friends & 68 & 74 & 18 & 36 \\
\hline Excursion & 12 & 13 & 4 & 8 \\
\hline Cinema & 5 & 6 & 2 & 4 \\
\hline Theatre & 4 & 6 & 1 & 3 \\
\hline Library & 8 & 14 & 7 & 13 \\
\hline Concert/Festival & 5 & 8 & 3 & 5 \\
\hline Street performance & 5 & 7 & 2 & 4 \\
\hline Nightclub/Bar & 4 & 6 & 1 & 2 \\
\hline Café/Tea room & 43 & 54 & 4 & 13 \\
\hline Museum & 3 & 4 & 1 & 3 \\
\hline Art exhibition & 3 & 4 & 1 & 3 \\
\hline Attend sports event & 12 & 19 & 1 & 4 \\
\hline Play sport & 24 & 33 & 4 & 13 \\
\hline Mean number of activities & 1.9 & 2.5 & 0.5 & 1.1 \\
\hline Average minutes per day watching television & 161 & 155 & 205 & 195 \\
\hline Average hours per day using internet & 2.6 & 3.4 & 3.1 & 3.7 \\
\hline Ever been abroad & 2 & 4 & $<1$ & 2 \\
\hline $\mathrm{N}=$ & 1848 & 2420 & 1524 & 2064 \\
\hline
\end{tabular}


There was still a digital divide within the countries, but most young people were on the 'right' side. Table 3 lists the percentages of the combined samples who were making different 'at least weekly' uses of the internet.

Leisure participation rates were generally lowest in Egypt (see Table 4), the country where incomes from employment were lowest, which confirms the significance of money in accessing leisure opportunities. However, in every country we found the same gender differences: men 'do more' except that females were spending more time watching television and also online in all countries where this information was collected (in Morocco the question was not asked).

Forthwith, when presenting our leisure findings, so as to prevent the main findings being submerged in a data deluge, we list only the most common forms of leisure activity - going out with friends, visiting cafes or tearooms, and playing sport - plus average number of activities in the relevant socio-demographic groups, and time spent watching television and online.

A second feature that makes the North Africa context 'different' is the dominant religion: Arabic versions of Islam. The samples were questioned about the importance of religion in 14 of their life domains. Answers were on a 1-5 scale with 1 meaning 'extremely important' and 5 meaning 'not important at all'. The composite mean scores in all the countries are beneath the mid-point of 3, indicating high levels of religiosity (see Table 5). There has been no loss of faith, and certainly no 'rise of no religion' as recorded in some European countries (Woodhead 2016), among the region's youth.

Levels of religiosity were related to levels of leisure participation. High levels of religiosity were positively associated with levels of leisure activity, especially among males (see Table 6). However, religiosity was not making any difference to time spent watching television or online. The Islam of the region's youth is not austere. Our evidence confirms Janmohamed's claim about young modern Moslems (her Generation $M$ ), using Islam as a prism through which to embrace modernity in all its aspects, including its branded products and consumer cultures (Janmohamed 2016).

Table 3 How often do you use the internet for? (4 countries)

\begin{tabular}{llc}
\hline At least once a week & Males & Females \\
& $\%$ & 73 \\
\hline Reading and writing emails & 74 & 87 \\
Chatting with a friend & 89 & 81 \\
Surfing general cultural sites & 79 & 69 \\
Surfing news websites & 74 & 69 \\
Downloading songs, films or TV programmes & 75 & 44 \\
Playing video games & 64 & 93 \\
Going on social networks (Facebook, Twitter etc) & 95 & 32 \\
Using adult websites & 46 & 56 \\
Using religious websites & 62 & 48 \\
Using dating websites & 61 & 31 \\
Using activist blogs and websites (political, human rights etc) & 36 \\
Looking for work or sending CVs & 39 & 25 \\
Shopping online & 42 & 35 \\
\hline
\end{tabular}


Table 4 Uses of free time by countries, all ages (in percentages)

\begin{tabular}{lllll}
\hline & Algeria & Egypt & Morocco & Tunisia \\
\hline Take part at least once a week & & & & \\
Males & & & & \\
$\quad$ Go out with friends & 88 & 58 & 56 & 70 \\
Café/Tea room & 62 & 37 & 31 & 24 \\
Play sport & 46 & 13 & 30 & 2.1 \\
Mean number of activities & 2.8 & 1.3 & 2.7 & 130 \\
Average minutes per day watching television & 143 & 157 & 201 & 3.6 \\
Average hours per day using internet & 3.0 & 2.7 & & 998 \\
N & 1064 & 979 & 1207 & 32 \\
Females & & & & 14 \\
Go out with friends & 34 & 11 & 40 & 11 \\
Café/tea room & 10 & 1 & 14 & 0.8 \\
Play sport & 13 & 1 & 13 & 177 \\
Mean number of activities & 1.0 & 0.2 & 1.8 & 4.1 \\
Average minutes per day watching television & 186 & 230 & 245 & 1001 \\
Average hours per day using internet & 3.2 & 2.9 & & 647 \\
N = & 949 & 991 & & \\
\hline
\end{tabular}

However, it is North Africa-specific features of young adults' family and housing transitions that suggest that any life-cycle squeeze on both sexes' leisure activities is likely to be muted. Custom in the region insists that men and women must marry and become parents in order to be considered fully adult. This presents different challenges for young men and young women. Custom also dictates that a

Table 5 Mean ratings of importance of religion, all ages (range 1.0-5.0, low scores $=$ high)

\begin{tabular}{lllll}
\hline & Algeria & Egypt & Morocco & Tunisia \\
\hline Clothing & 1.8 & 1.6 & 2.2 & 2.0 \\
Appearance & 1.9 & 1.6 & 2.2 & 2,0 \\
Food & 1.8 & 2.0 & 2.2 & 2.0 \\
Political choice & 2.9 & 3.8 & 2.6 & 3.2 \\
Emotional relationships & 2.3 & 2.9 & 2.4 & 2.1 \\
Place of work & 2.0 & 2.9 & 2.3 & 2.1 \\
Commercial transactions & 2.1 & 3.8 & 2.4 & 2.2 \\
Marriage & 1.7 & 2.0 & 2.3 & 1.7 \\
Relationships with opposite sex & 2.0 & 2.6 & 2.3 & 1.9 \\
Nature of job & 1.9 & 2.8 & 2.3 & 2.0 \\
Relationships with neighbours & 1.9 & 1.9 & 2.3 & 2.1 \\
Travel & 2.6 & 3.5 & 2.4 & 3.0 \\
Culture and leisure & 2.2 & 2.9 & 2.4 & 2.5 \\
Family celebrations & 2.1 & 2.4 & 2.3 & 2.4 \\
Composite means & 2.1 & 2.6 & 2.3 & 2.2 \\
\hline
\end{tabular}


Table 6 Uses of free time by religiosity, all ages (in percentages)

\begin{tabular}{lllll}
\hline & $\begin{array}{l}\text { Males } \\
\text { High religiosity }\end{array}$ & $\begin{array}{l}\text { Males } \\
\text { Moderate and } \\
\text { low religiosity }\end{array}$ & $\begin{array}{l}\text { Females } \\
\text { High religiosity }\end{array}$ & $\begin{array}{l}\text { Females } \\
\text { Moderate and } \\
\text { low religiosity }\end{array}$ \\
\hline $\begin{array}{l}\text { Take part at least once a week } \\
\text { Go out with friends }\end{array}$ & 76 & 65 & 32 & 24 \\
$\begin{array}{l}\text { Café/tea room } \\
\begin{array}{l}\text { Play sport } \\
\text { Mean number of activities }\end{array}\end{array}$ & 54 & 44 & 10 & 9 \\
$\begin{array}{l}\text { Average minutes per day } \\
\text { watching television }\end{array}$ & 157 & 21 & 11 & 7 \\
$\begin{array}{l}\text { Average hours per day } \\
\text { using internet }\end{array}$ & 3.2 & 2.0 & 0.9 & 0.8 \\
$\mathrm{~N}=$ & 158 & 199 & 198 \\
\hline
\end{tabular}

groom or his family must cover the costs of a wedding (celebrations, gifts for the bride's family and maybe a dowry), and provide a home for the couple.

Among the 25-29 year olds in our samples, 56\% of the women but as many as $86 \%$ of the males were still single. Males needed to delay marriage and transition through a prolonged 'waithood', until they earned enough or inherited property to enable them to pay for a wedding and to establish and finance an independent household (see Dhillon et al. 2009). For young women the problem was finding a male with these capabilities. This usually meant being willing to marry an older man. So in $26 \%$ of the marriages in which the couple were living independently of their families of origin, the husband was more than 10 years older than the wife, between five and 10 years older in another $36 \%$ of the marriages, and up to four years older in $34 \%$. The women who were most likely to be married when aged 25-29 were those who had remained inactive in the labour market. They had lower rates of participation in out-of-home leisure than same-aged peers who had any kind of employment. This meant that there was little leisure activity that could be squeezed. Males who married at age 25-29 or younger had necessarily taken brides close to their own age, and the couples were most likely to be living with the husbands' parents, an arrangement that most young women in the region consider unacceptable (Population Council 2011). The older grooms, outside the age range covered in our survey, had typically been able to offer the brides independent households and the leisure of these husbands' leisure may have been especially subject to a life-cycle squeeze. The married males within our sample's age range were mostly among the minorities who had decently paid (by local standards), formal jobs with employment contracts of indefinite duration, or had businesses which supplied them with above-average incomes. Even so, they had mostly continued living with their own parents where they were joined by their wives. So they were likely to be in households where they could leave housework and any child care to their wives, mothers and any co-resident sisters, thereby escaping any life cycle squeeze on their leisure. Our evidence enables us to discover what was actually happening. 


\subsection{Leisure Trends with Age}

Our main finding is that, with marital status held constant, there were no general trends in leisure participation between ages 15 and 29 (see Table 7). This applied equally to males and females. Among single males, going out with friends declined slightly between 15 and 19 and 20-24, then rose to a peak within the 25-29 age band. Visiting cafes and tearooms rose progressively from 40\% among 15-19 year olds, up to 59\% among those aged 25-29. In contrast, sport participation declined gradually from 39\% to $25 \%$. The average number of activities in which single males took part at least once a week rose from 2.4 to 2.7 then fell back to 2.4. Time spent watching television and online fluctuated but with no overall trend. Among single women rates of participation in sport and going out with friends were stable across our age bands whereas the proportions visiting cafes and tearooms rose progressively from $8 \%$ to $15 \%$. Time spent watching television and online was stable throughout. The average number of activities in which single women took part at least once a week was stable at 1.3 between the 15-19 and 20-24 age bands, then feel back to 1.0.

Among married women there was a general downward trend in leisure participation with age, possibly as the arrival of children made increasing demands. The proportions going out with friends, visiting cafes and tearooms and playing sport all declined with age. However, the average number of activities in which married women took part at least once a week fluctuated but with no clear trend: 0.4 to 0.5 than downward to 0.3 . More time was spent watching television with increasing age, and less time was spent online. Among married men, as among the married females, there was a downward trend with age in going out with friends, visiting cafes and tearooms, and playing sport, whereas time spent

Table 7 Uses of free time by age and marital status (in percentages)

\begin{tabular}{lllllll}
\hline & $\begin{array}{l}15-19 \\
\text { single }\end{array}$ & $\begin{array}{l}15-19 \\
\text { married }\end{array}$ & $\begin{array}{l}20-24 \\
\text { single }\end{array}$ & $\begin{array}{l}20-24 \\
\text { married }\end{array}$ & $\begin{array}{l}25-29 \\
\text { single }\end{array}$ & $\begin{array}{l}25-29 \\
\text { married }\end{array}$ \\
\hline Take part at least once a week & & & & & & \\
Males & & & & & & \\
Go out with friends & 72 & 77 & 70 & 65 & 75 & 62 \\
Café/Tea room & 40 & 59 & 50 & 52 & 59 & 48 \\
Play sport & 34 & 39 & 28 & 29 & 25 & 19 \\
Mean number of activities & 2.4 & 1.5 & 2.7 & 1.3 & 2.4 & 1.6 \\
Average minutes per day watching television & 158 & 170 & 159 & 141 & 153 & 160 \\
Average hours per day using internet & 3.4 & 2.7 & 3.4 & 2.8 & 3.2 & 2.8 \\
N = & 1328 & 87 & 1411 & 226 & 873 & 551 \\
Females & & & & & & \\
Go out with friends & 39 & 21 & 35 & 15 & 35 & 10 \\
Café/Tea room & 8 & 8 & 12 & 5 & 15 & 7 \\
Play sport & 12 & 9 & 11 & 4 & 10 & 4 \\
Mean number of activities & 1.3 & 0.4 & 1.3 & 0.5 & 1.0 & 0.3 \\
Average minutes per day watching television & 187 & 220 & 192 & 221 & 190 & 217 \\
Average hours per day using internet & 3.7 & 2.9 & 3.8 & 3.2 & 4.0 & 3.3 \\
N = & 1029 & 129 & 821 & 481 & 442 & 686 \\
\hline
\end{tabular}


watching television and online remained stable. The average number of activities in which successive age bands participated at least weekly declined from 1.5 to 1.3 then rose to 1.6.

These mixed findings are interesting because in Lebanon, a neighbouring country on the Mediterranean's eastern shore, where matched samples were investigated using an identical interview schedule, there was a clear downward trend in participation in our listed leisure activities with age (see Roberts and Kovacheva 2016). We have kept Lebanon separate from the four North Africa countries in the research project because it was much more prosperous - typical incomes from employment were roughly twice as high, unemployment was lower, and a higher proportion of young people were becoming university graduates - than any of the North Africa countries. Probably more important, Lebanon is culturally different. The population is a complex mixture of Moslem and Christian ethnoreligious communities, 18 of which have fixed representation in the parliament, government and public administration. The country is known as the Levant - the gateway to the east. The capital, Beirut, has been called 'the Paris of the East'. When things go well, Beirut is a thriving, cosmopolitan commercial and cultural hub, but its buildings bear the scars of 'bad times' when the region's wars have spread into the country. Lebanon's young people are less religious, and the country is more Westernised than any of the North Africa countries. The initial demonstrations in Beirut in 2011 (part of the Arab Spring) had civil marriages as the main demand which would have eliminated the need for mixed faith couples to choose to marry in the church or mosque of one of the partners. One driver of change in leisure behaviour between ages 15 and 29 in Lebanon is absent in North Africa. In all the countries young people progressively leave education and the daily contact with friends that this offers. In the Lebanon this was leading to less time being spent going out with groups of friends, and as cohorts grew older more time was spent in couples. This does not happen in North Africa.

Most married couples in the North Africa samples had met each other through their extended families or from their neighbourhoods. Prospective brides and grooms were known to and approved by both sets of families. It had been rare for matches leading to marriage to be made in education, workplaces or during free time. The differences in the proportions of the sexes who went out with friends at least weekly (70\% of 20-24 year old single males and $35 \%$ of young single women), and who visited cafes or tearooms weekly or more frequently (50\% and $12 \%$ ), show that most young men could not anticipate chance meetings with future spouses. Sexual experiences were more likely to be found on adult websites, visited at least weekly by $46 \%$ of 15-29 year old males and $32 \%$ of females. Flirting on dating websites was even more popular: $61 \%$ of males and $48 \%$ of the young women were at least weekly visitors. Relationships formed and acted out online were for fun and maybe thrill, not serious searches for lifetime partners. The modern Western norm is to marry for love and then hope that love endures. In Arab Islamic contexts the norm is to marry first then trust that love will develop.

\subsection{The Leisure Consequences of Marriage}

Here Table 7 presents a very clear picture. Among young women, all the single/married comparisons within age bands, except visits to cafes and tearooms among 15-19 year olds, show the marriage is associated with reductions in out-of-home leisure activities. Time spent online also declines. The reverse is true with time spent watching television which is greater among married women. 
With husbands the picture is chequered. Within the 25-29 age band there are no exceptions to the same trend found among women - with marriage there is an all-round reduction in out-of-home leisure activity. This applies to the proportions who go out with friends, visit cafes or tearooms, and play sport at least weekly, and also to time spent online. The average number of activities in which men took part at least weekly declined from 2.4 to 1.6 on marriage. Among younger singles and husbands the findings are more mixed except that there are always declines in the average number of leisure activities practised at least weekly and also in time spent online. However, among 15-19 year olds, participation rates in sport, visiting cafes and tearooms, and going out with friends do not decline on marriage. This is also the case with 20-24 year old married men where there are no reductions in the proportions playing sport and visiting cafes or tearooms at least once a week.

Thus our findings from North Africa are in-line with results consistently achieved in Western research: men and women experience a squeeze on out-of-home leisure on marriage, but this squeeze is more consistent across age bands and leisure activities, and more severe, for women than for men. However, our large data set allows us to take the analysis a step further. We have noted earlier that the marriages of our respondents could be split into two groups. The 15-29 year old women who had married had usually been partnered by older men who were able to provide independent family households. The 15-29 year old males who had married had usually taken their brides into the households of the husbands' parents. Maybe it was the household situations of the married men in our sample that was lessening the severity of the life cycle squeeze. Maybe the results become similarly mixed among married women if we separate those who marry heads of household from those who move-in with in-laws.

\subsection{Housing Transitions}

The evidence in Table 8 shows emphatically that, among males, this was not the case. Rather than the costs of providing independent households and enhanced in-home responsibilities reducing out-of-home leisure, the heads of household had higher participation rates than other husbands in going out with friends, visiting cafes and tearooms, and playing sport. The average number of activities in which they took part at least weekly was 2.1 against 1.4 for the other husbands. The heads of household were spending slightly less time watching television and also online.

Among the married women, overall rates of participation in out-of-home activities were lower, of course, and the spouses of heads of households did not consistently engage in more or fewer activities than other wives. The latter were the more likely to go out with friends at least weekly (18\% and 10\%) whereas the spouses of household heads were the more likely to visit cafes and tearooms and play sport. The average number of activities in which the two groups of wives participated were very similar ( 0.5 and 0.4 ), as were the hours per day that they spent watching television. The wives of heads of household were spending somewhat less time per day online (an average of 3.1 against $3.4 \mathrm{~h}$ for other wives).

This evidence suggests strongly that it is marriage rather than housing transitions that curtail women's out-of-home leisure in North Africa countries, whilst men who provide their wives with independent households are better able than other husbands to maintain their own out-of-home leisure. This could be on account of the superior jobs 
Table 8 Uses of free time by marital and housing status

Take part at least once a week

a. Married males by housing status (in percentages)

Go out with friends

Café/tea room

Play sport

Mean number of activities

Average minutes per day watching television

Average hours per day using internet

$\mathrm{N}=$

Take part at least once a week

b. Married females by housing status (in percentages)

Go out with friends

$10 \quad 18$

Café/tea room

Play sport

Mean number of activities

Average minutes per day Watching television

and incomes of the male heads of household and/or to their in-home status vis-a-vis their typically younger wives.

\section{Discussion and Conclusions}

Our research shows that the life cycle squeeze on leisure during young adults' family and housing life stage transitions does operate across North Africa. Young single women's leisure is not so spartan that there is too little to squeeze further. The societies are not so patriarchal that men's our-of-home leisure is maintained throughout. We have been able to disaggregate and show that it is marriage, not moving into an independent household, that makes the major difference to participation in out-of-home leisure in North Africa, but we are unable to say whether this will apply in other times and places.

A question that remains unanswered is whether 'squeeze' is the most appropriate concept to describe these life cycle changes. Early in the history of leisure research in the UK, Alan Tomlinson (1979) found that a group of women in his adult education class had no regrets about exchanging the leisure of their childhoods and youth for a different, married way of life. However, at the same conference Dorothy Hobson (1979) reported that her sample of younger women did regret the passing of, and still yearned for, the lives that they had enjoyed before marriage, when they had gone out regularly to discos with girlfriends. This debate has never been resolved, though for 30-plus years what was originally the Tomlinson side has been relatively silent. Leisure researchers have tended to assume that if people do not participate in an activity this must be due to some kind of constraint, and the leisure being examined is invariably an out-of-home variety. Our results, 
like those of other researchers, are silent on how young women and men balance the gains and losses when they exchange former levels of participation in out-of-home activities for whatever different leisure experiences that they derive from home and family life. This is an issue for further research in North Africa, and in other countries. Answers are likely to differ from couple to couple, from country to country, and between socio-demographic groups within countries. However, North Africa researchers will know that these are countries where young adults' family and housing transitions are made in a context where they will be accepted as fully adult when, and not before, they have married, become parents, and are the senior adults in their households.

We cannot claim universality for the life cycle squeeze having added evidence solely from North Africa. However, we have shown that this squeeze is not confined to the occident. It is likely to occur in any society where not only paid work, but also many opportunities to spend time and money on, and to enjoy entertainment and sociability, are located outside the home, and where the nuclear family is the normal residential unit. The squeeze will impinge most heavily on women wherever they have the major responsibility for family and home care. Common structural features of modern societies will have some similar leisure consequences everywhere. Participation in leisure activities throughout and beyond the Western world appears equally conducive to personal wellbeing (Kwai-Sang and Packer 2002). Thus the sociology of leisure can aspire to identify some universal truths, most easily if it restricts its gaze to societies which have become modern or which are modernising.

However, there are ways in which the leisure of all age groups across North Africa is different, and not just the low profile of alcohol. In countries with authoritarian governments, popular cultures, especially music, become important media for expressing dissent (see Gana 2013; Skalli 2013). The sounds of Western popular music can be heard across North Africa, but local sounds make louder and more widespread noise. Traditional Asian cultures, like traditional occidental cultures, and just like ArabMoslem cultures, can remain alive and continue to gain expression in modern leisure. Young modern Moslems in North Africa embrace modern consumerism as a means of expressing their distinctive tastes, and the same is most likely to happen throughout Asia, alongside the life cycle squeeze on their out-of-home leisure.

Open Access This article is distributed under the terms of the Creative Commons Attribution 4.0 International License (http://creativecommons.org/licenses/by/4.0/), which permits unrestricted use, distribution, and reproduction in any medium, provided you give appropriate credit to the original author(s) and the source, provide a link to the Creative Commons license, and indicate if changes were made.

\section{References}

Barrell, G., Chamberlain, A., Evans, J., Holt, T., \& Mackean, J. (1989). Ideology and commitment in family life: The case of runners. Leisure Studies, 8, 249-262.

Bekuis, H., Lubbers, M., \& Ultee, W. (2014). A macro-sociological study into the changes in the popularity of domestic, European, and American pop music in western countries. European Sociological Review, 30, 180-193.

Dhillon N, Dyer P and Yousef T (2009) Generation in waiting: an overview of school to work and family formation transitions In Dhillon N and Yousef T (Eds.), Generation in Waiting: The Unfulfilled Promise of Young People in the Middle East. Brookings Institute Press, Washington DC, 11-38.

Eisenstadt, S. N. (2000). Multiple modernities. Daedalus, 129, 1-29.

Estes, R. J., \& Wilenski, H. (1978). Life-cycle squeeze and the morale curve. Institute of Industrial Relations. Reprint 422. Berkeley: University of California. 
Farsoun, S. (2006). Class structure and social change in the Arab world. In N. Hopkins \& S. Ibrahim (Eds.), Arab society: Class, gender, power, and development (pp. 1-28). Cairo: American University in Cairo Press.

Fishwick, L., \& Hayes, D. (1989). Sport for whom? Differential participation patterns of recreational athletes in leisure time physical activities. Sociology of Sport Journal, 6, 269-277.

Fukuyama, F. (1992). The end of history and the last man. London: Penguin.

Gana, N. (2013). Visions of dissent: Voices of discontent: Postcolonial Tunisian film and song. In N. Gana (Ed.), The making of the Tunisian revolution: Contexts, architects, prospects (pp. 181-203). Edinburgh: Edinburgh University Press.

Gershuny, J. (2003). Time through the lifecourse. In the family. ISER working paper (pp. 2003-2003). Colchester: University of Essex.

Hesmondhalgh, D. (2013). The cultural industries (3rd ed.). London: Sage.

Hobson, D. (1979). Working class women, the family and leisure. In Z., Strelitz (Ed.), Leisure and family diversity. Leisure studies association conference papers 9, London.

Ibrahim, H. (1982). Leisure and Islam. Leisure Studies, 1, 197-210.

Iwasaki, Y., Nishino, H., Onda, T., \& Bowling, C. (2007). Leisure research in a global world: Time to reverse the western dominance in leisure research. Leisure Sciences, 29, 113-117.

Janmohamed, S. (2016). Generation M: Young Muslims changing the world. London: Tauris.

Kwai-Sang, Y., \& Packer, T. L. (2002). Health and well-being through t'ai chi: Perceptions of older adults in Hong Kong. Leisure Studies, 21, 163-178.

Leitner, M. J., \& Leitner, S. F. (Eds.). (2014). Israeli life and leisure in the $21^{\text {st }}$ century. Urbana: Sagamore.

Ma, H., \& Lui, E. (2017). Traditional Chinese leisure culture and economic development: A conflict of forces. New York: Palgrave Macmillan.

Martin, W. H., \& Mason, S. (2003). Leisure in three middle eastern countries. World Leisure Journal, 45(1), $35-44$.

Martin, W. H., \& Mason, S. (2004). Leisure in an Islamic context. World Leisure Journal, 46(1), 4-13.

Martinelli, A. (2007). Transatlantic divide: Comparing the United States and the European Union. Oxford: Oxford University Press.

Nilan, P., \& Feixa, C. (2006). Global Youth? Hybrid Identities, plural worlds. London: Routledge.

Nimrod, G. (2007). Retirees' leisure: Activities, benefits and their contribution to life satisfaction. Leisure Studies, 26, 65-80.

Nimrod, G. (2014). The benefits of and constraints to participation in seniors' online communities. Leisure Studies, 33, 247-266.

Population Council. (2011). Survey of young people in Egypt. Cairo: Population Council.

Rapoport, R., \& Rapoport, R. N. (1975). Leisure and the family life-cycle. London: Routledge.

Roberts, K. (2016). The business of leisure. London: Palgrave.

Roberts, K., \& Kovacheva, S. (2016). Use of free time by young people, and social inclusion and exclusion in Lebanon. International Journal of Social Science and Economic Research, 1, 1190-1214.

Robinson, J. P., \& Godbey, G. (1999). Time for life: The surprising ways Americans use their time (second ed.). Penn State: Pennsylvania State University Press.

Sivan A (2000) Global influence and local uniqueness: the case of adolescent leisure in Hong Kong. World Leisure Journal, 42, 4, 24-32.t.

Skalli, L. H. (2013). Youth, media and the politics of change in North Africa: Negotiating identities, spaces and power. Middle East Journal of Culture and Communication, 6, 5-14.

Smith, J. (1987). Women at play: Gender, the life-cycle and leisure. In J. Horne, D. Jary, \& A. Tomlinson (Eds.), Sport, leisure and social relations. London: Routledge.

Stebbins, R. A. (2013). Work and leisure in the Middle East: The common ground of two separate worlds. New Brunswick: Transaction Publishers.

Sullivan, O. (2010). Changing differences by educational attainment in fathers' domestic labour and child care. Sociology, 44, 716-733.

Tomlinson, A. (1979). Leisure, the family and women's role: Observations on personal accounts. In Z. Strelitz (Ed.), Leisure and family diversity. Leisure studies association conference papers, 9. London.

Venn, S., Arber, S., Meadows, R., \& Hislop, J. (2008). The fourth shift: Exploring the gendered nature of sleep disruption among couples with children. British Journal of Sociology, 59, 79-98.

Wearing, B. (1993). The family that plays together stays together: Or does it? Leisure and mothers. World Leisure and Recreation, 35(3), 25-29.

Woodhead, L. (2016). The rise of "no religion". In Britain: The emergence of a new cultural majority. Journal of the British Academy, 4 (pp. 245-261). 